\title{
Occurrence of malignant glaucoma after laser iridotomy
}

\author{
ANNE M V BROOKS, C A HARPER, AND W E GILLIES \\ From the Glaucoma Investigation and Research Unit, the Royal Victorian Eye and Ear Hospital, \\ East Melbourne, Victoria 3002, Australia
}

SUMMARY A case is described of malignant glaucoma with extreme shallowing of the anterior chamber (AC) and an abnormally high intraocular pressure (IOP) following laser iridotomy for acute angle closure glaucoma. The episode followed the use of strong miotic (pilocarpine hydrochloride $4 \%$ ) and was reversed by mydriatics including phenylephrine hydrochloride. Serial estimation of anterior chamber depth is important in the management of angle closure glaucoma.

Malignant glaucoma has been described as a condition in which, after operation for glaucoma, the anterior chamber (AC) becomes extremely shallow or flat and the intraocular pressure (IOP) abnormally high.' 2 Cases have been reported after peripheral iridectomy ${ }^{2.5}$ and may even occur when strong miotics are used in the presence of a shallow anterior chamber without surgical operation. ${ }^{-n}$ So far we

Correspondence to Dr W E Gillies, 82 Collins Street, Melbourne, Victoria 3000, Australia.

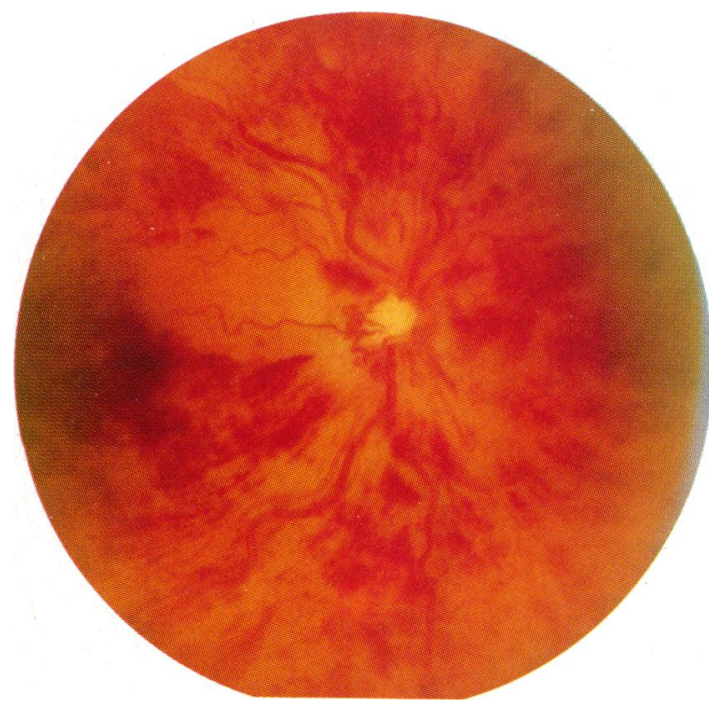

Fig. 1 Fundus appearance of right eye showing haemorrhagic central retinal vein occlusion. The cup-disc ratio is $0 \cdot 5$. believe no case has been reported following laser iridotomy.

\section{Case Report}

A 73-year-old white Caucasian male was admitted to hospital on 5 March 1988 with a one-day history of a painful right eye. He was a smoker and alcoholic on methyldopa (Aldomet) $250 \mathrm{mg}$ three times a day and had extensive peripheral vascular disease, with a right above-knee amputation.

The visual acuities were $\mathrm{R} 6 / 36, \mathrm{~L} 6 / 18$. The $\mathrm{R}$ pupil was semidilated and poorly reactive to light. There were $2+$ cells in the right $\mathrm{AC}$, and the IOPs by Goldmann applanation were R 56, L $18 \mathrm{mmHg}$. The irides were grey and normal. On gonioscopy the $\mathbf{R}$ angle was closed all around. The $L$ angle was narrow with a small slit open all around. There was a $\mathbf{R}$ central retinal vein occlusion with macular oedema (Fig. 1). The optic cup disc ratio was $0.5 \mathrm{R}$ and $\mathrm{L}$.

On 8 March following treatment of the $R$ eye, with pilocarpine hydrochloride $4 \%$ four times daily, timolol maleate (Timoptol) $0 \cdot 25 \%$ twice daily, prednisolone acetate (Prednefrin forte) $1 \%$ four times daily, and acetazolamide (Diamox) $250 \mathrm{mg}$ four times daily orally the R IOP was 16 and the L 12 $\mathrm{mmHg}$. The corneal thickness was $0.56 \mathrm{~mm}$ and AC depth $1.3 \mathrm{~mm} R$ and $L$ as measured with the HaagStreit pachymeter. The $\mathbf{R}$ angle was open all round.

The patient underwent a YAG laser peripheral iridotomy of seven burns at $6.9 \mathrm{~mJ}$ in the R eye and 10 burns at $7.0 \mathrm{~mJ}$ in the $\mathrm{L}$ eye. In each eye a cloud of pigment was released into the $\mathrm{AC}$ with a gush of aqueous on complete penetration of the iris. 


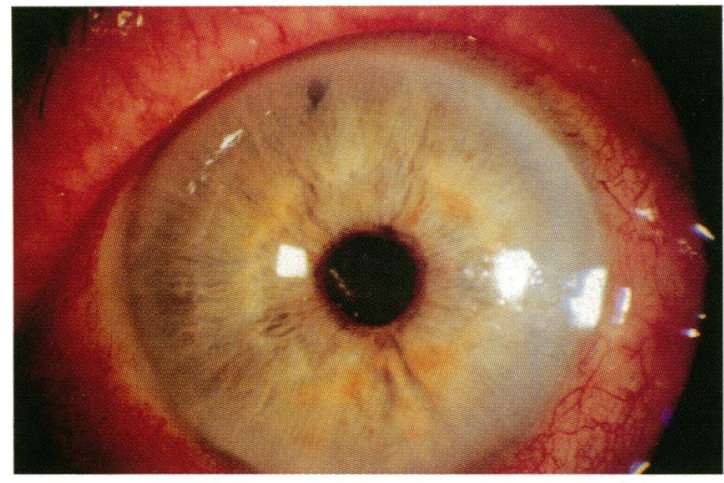

Fig. 2 Slit-lamp appearance of the affected right eye showing patent peripheral iridotomy and normal iris architecture.

The initial iridotomy was enlarged somewhat in each case until the iridotomy was obviously patent on slitlamp examination (Figs. 2, 3).

On 11 March the IOP was R $32, \mathrm{~L} 30 \mathrm{mmHg}$ on only timolol maleate and fluorometholone (FML) $0.1 \%$ four times daily, and pilocarpine hydrochloride $4 \%$ four times daily was recommenced in each eye. On 13 March the IOP was R 46, L $18 \mathrm{mmHg}$, and the right $\mathrm{AC}$ depth was extremely shallow, being only 0.7 $\mathrm{mm}$, while on the left it was $1.7 \mathrm{~mm}$. The $R$ angle was closed all round (Fig. 4). The L angle was open (Fig. 5). A provisional diagnosis of right malignant glaucoma was made, and acetazolamide $250 \mathrm{mg}$ four times daily by mouth was started with homatropine hydrobromide (Homatropine) $5 \%$ and pheny-

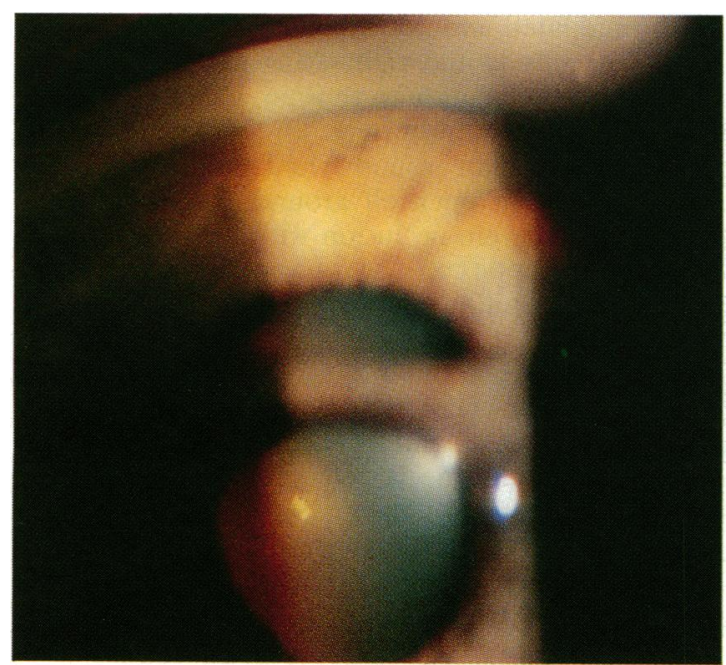

Fig. 4 Gonioscopic appearance of right eye showing the angle closed by iridocorneal apposition with moderate bowing of the iris.

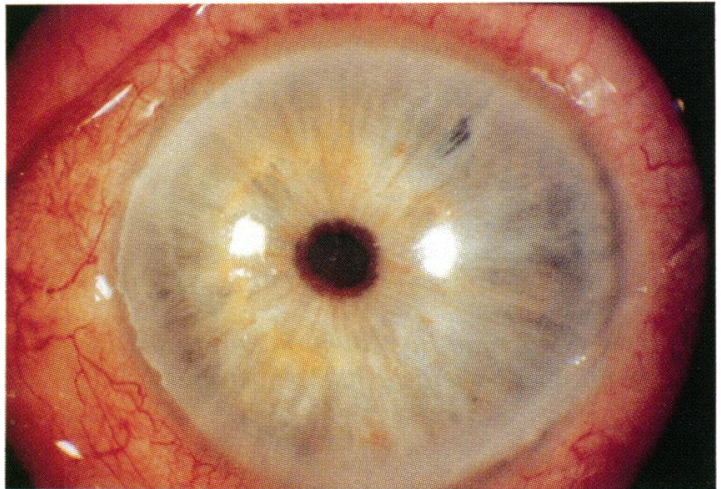

Fig. 3 Slit-lamp appearance of the fellow left eye showing patent peripheral iridotomy and normal iris architecture.

lephrine hydrochloride (Neosynephrine) 10\% . On 17 March the right $\mathrm{AC}$ had deepened to $1.5 \mathrm{~mm}$, the $\mathrm{L}$ was $1.7 \mathrm{~mm}$, and the IOP was R 21, L $15 \mathrm{mmHg}$. The $\mathrm{R}$ angle was now open (Fig. 6).

Panrentinal photocoagulation was performed on the $R$ eye in two sittings (422 and 622 spots of $200 \mu \mathrm{m}$ at $0.4-0.6$ watt intensity and 0.1 second duration). On 25 March phenylephrine hydrobromide was stopped because of a local allergy. He was discharged from hospital on timolol maleate $0.25 \%$ twice daily and atropine sulphate $1 \%$ daily to the $\mathrm{R}$ eye and pilocarpine hydrochloride $4 \%$ four times daily to the $\mathrm{L}$ eye.

At follow-up on 12 April the IOP was R 55, L $17 \mathrm{mmHg}$. The $\mathrm{R}$ angle was closed above but open

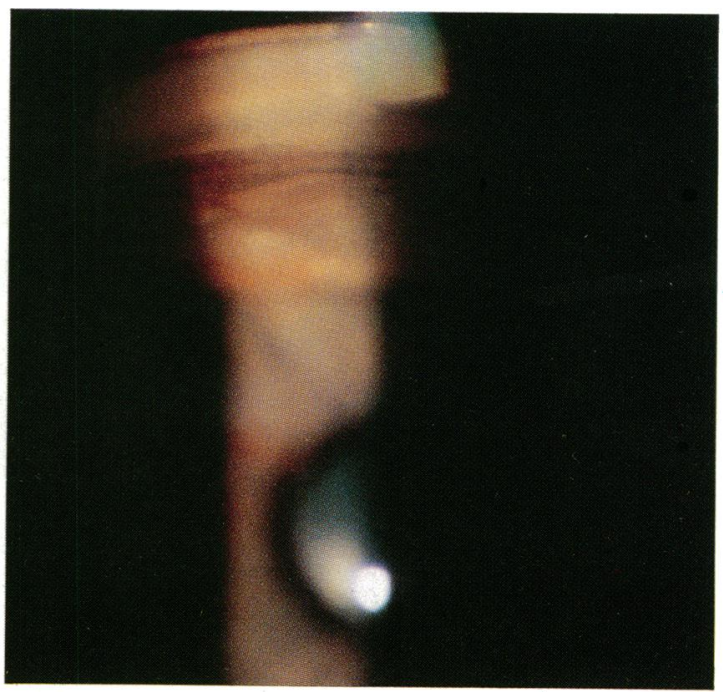

Fig. 5 Gonioscopic appearance of left open angle with slight bowing of the iris and moderate trabecular pigmentation. 


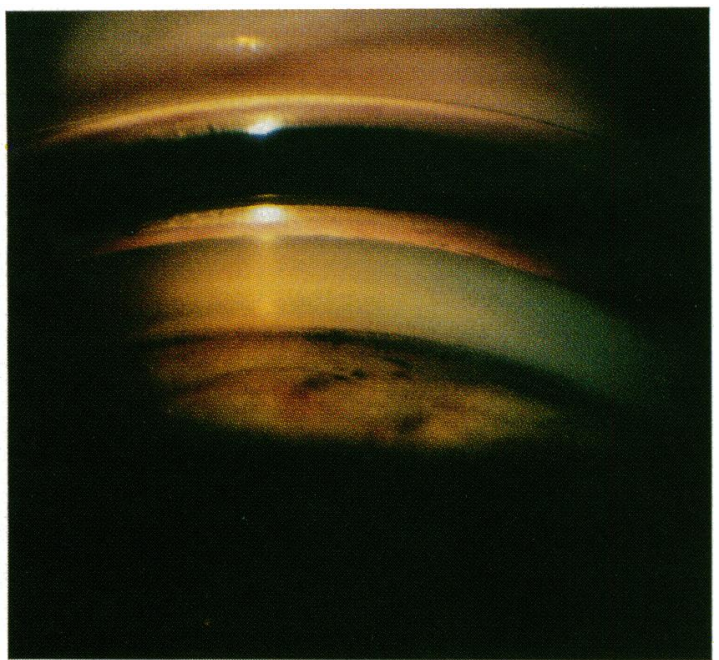

Fig. 6 Gonioscopic appearance of right angle below, now open, with marked pigmentation along the line of the canal of Schlemm.

below from 4 to 6 o'clock, with $80 \%$ peripheral anterior synechiae. The R AC depth was $1.6 \mathrm{~mm}$. Atropine was stopped, and he was given timolol maleate $0.25 \%$ twice daily.

On 7 June 1988 he attended after having been off eyedrops for two weeks. The AC depth was R 1.6 $\mathrm{mm}, \mathrm{L} 1.7 \mathrm{~mm}$, the IOP was R $26, \mathrm{~L} 24 \mathrm{mmHg}$, and both angles were open. Timolol maleate $0.25 \%$ twice daily was started again but he was lost to follow-up.

\section{Discussion}

Shaffer discussed the possibility of ciliolenticular block initiated by the use of strong miotics in an unoperated eye causing malignant glaucoma when the ciliary body and the edge of the lens entrapped the aqueous flow, so that aqueous did not enter the $\mathrm{AC}$, leading to extreme shallowing of the $\mathrm{AC}$, angle closure, and malignant glaucoma. ${ }^{910}$

Lowe ${ }^{11}$ noted that following peripheral iridectomy for angle closure half to two thirds of these narrow angles may close with pupillary dilatation by mydriatics, adrenaline-like mydriatics being safer than tropine-like mydriatics. ${ }^{12-14}$

In the present case a high rise in IOP with extreme shallowing of the AC followed the use of pilocarpine hydrochloride $4 \%$ after a patent laser iridotomy had been performed, a finding consistent with Shaffer's observations. " "1" The AC deepened and the IOP fell to a normal level with phenylephrine hydrochloride $10 \%$ and homatropine hydrobromide $5 \%$. However, when the phenylephrine hydrochloride was discontinued and the patient discharged on atropine sulphate $1 \%$, the angle closed once more, with an abnormally high rise in IOP, though the AC did not become shallow, which is consistent with Lowe's observations. ${ }^{11-14}$

Thus, although the use of pilocarpine hydrochloride $4 \%$ caused extreme shallowing of the AC and a high rise in IOP, this was reversed by homatropine hydrobromide and phenylephrine hydrochloride, an adrenaline-like mydriatic. Dilatation with phenylephrine hydrochloride was probably crucial in breaking the ciliolenticular block, demonstrating the usefulness of this type of mydriatic after peripheral iridotomy in angle closure.

The late rise in IOP with angle closure but no shallowing of the AC following atropine sulphate demonstrates the tendency of strong tropine-like mydriatics to cause angle closure and a rise in IOP following iridotomy for angle closure.

The risk of some shallowing of the AC leading to angle closure glaucoma after central retinal vein occlusion is well known, ${ }^{15-17}$ but initially the AC depths were almost equal in this patient with central retinal vein occlusion, and the episode of a high rise in IOP with extreme shallowing of the AC preceded the use of panretinal photocoagulation.

This case shows that a condition consistent with malignant glaucoma may follow laser iridotomy for angle closure glaucoma, and it illustrates the previously described risks of both strong tropine-like mydriatics and strong miotics in such patients with very shallow ACs and an unstable lens iris diaphragm. It also emphasises the importance of serial estimation of anterior chamber depths in the management of difficult cases of angle closure glaucoma.

This work was carried out under Research Projects 101 and 126 of the Royal Victorian Eye and Ear Hospital, East Melbourne, Victoria 3002, Australia.

\section{References}

1 Von Graefe A. Beitrage zur pathologie und therapie des glaukoms. Graefes Arch Clin Exp Ophthalmol 1869; 15: 108-252.

2 Chandler PA. Malignant glaucoma. Trans Am Ophthalmol Soc $1950 ; 48 ; 128-43$.

3 Levene R. A new concept of malignant glaucoma. Arch Ophthalmol 1972; 87: 497-506.

4 Simmons RJ. Malignant glaucoma. In: Epstein DL, ed. Chandler and Grant's glaucoma. Philadelphia: Lea and Febiger, 1986: 264-78.

5 Chandler PA, Grant M. Mydriatic-cycloplegic treatment in malignant glaucoma. Arch Ophthalmol 1962; 68: 353-9.

6 Gorin G. Angle-closure glaucoma induced by miotics. Am J Ophthalmol 1966; 62: 1063-7.

7 Rieser JC, Schwartz B. Miotic-induced malignant glaucoma. Arch Ophthalmol 1972; 87: 706-12.

8 Merritt JC. Malignant glaucoma induced by miotics postoperatively in open-angle glaucoma. Arch Ophthalmol 1977; 95: 19889.

9 Shaffer RN. Role of vitreous detachment in aphakic and malignant glaucoma. Ophthalmology 1954; 58: 217-29. 
10 Shaffer RN. Suggested anatomic classification to define the pupillary block glaucomas. Invest Ophthalmol Vis Sci 1973; 12: $540-2$.

11 Lowe RF. Primary angle-closure glaucoma: investigations after surgery for pupil-block. Am J Ophthalmol 1964; 57: 931-8.

12 Lowe RF. Primary angle-closure glaucoma: postoperative tests with L-epinephrine base. Am J Ophthalmol 1964; 58: 581-3.

13 Lowe RF. Primary angle-closure glaucoma: investigations using $10 \%$ phenylephrine eyedrops. Am J Ophthalmol 1965; 60: 415-9.

14 Lowe RF. Angle-closure, pupil dilatation, and pupil block. Br J Ophthalmol 1966: 50: 385-9.
15 Grant WM. Shallowing of the anterior chamber following occlusion of the central retinal vein. Am J Ophthalmol 1973; 75: 384-9.

16 Hyams SW, Neumann E. Transient angle-closure glaucoma after retinal vein occlusion: report of two cases. Br JOphthalmol 1972: 56: 353-5.

17 Weber PA, Cohen JS, Baker D. Central retinal vein occlusion and malignant glaucoma. Arch Ophthalmol 1987: 105: 635-6.

Accepted for publication 12 January 1989. 